Article

\title{
Luminescent Properties of Oxazine 170 Perchlorate Doped PMMA Fiber
}

\author{
Piotr Miluski \\ Bialystok University of Technology, Wiejska 45D, 15-351 Bialystok, Poland; p.miluski@pb.edu.pl; \\ Tel.: +48-85-746-94-06 \\ Academic Editors: Giancarlo C. Righini, Shibin Jiang and Francesco Prudenzano \\ Received: 3 February 2017; Accepted: 10 April 2017; Published: 19 April 2017
}

\begin{abstract}
The article presents fabrication and luminescent properties of poly(methyl methacrylate) (PMMA) fiber doped by Oxazine 170 perchlorate. The bright fluorescence of polymeric fiber (at molar fluorescent organic dye concentration $4.3 \times 10^{-5}$ ) was characterized in terms of spectrum and signal attenuation vs. the fiber length. The significant changes in fluorescence spectrum $\left(\lambda_{\max }\right.$ red shift average slope $4.6 \mathrm{~nm} / \mathrm{cm}$ and Full Width at Half Maximum (FWHM) increasing slope $6.7 \mathrm{~nm} / \mathrm{cm}$ ) have been noticed for the length of the fiber $(0.02-0.08 \mathrm{~m})$ which corresponds to a high overlapping region of absorption and emission spectra of used dye. The red shift of $\lambda_{\max }$ (c.a. $80 \mathrm{~nm}$ ) was presented in fabricated polymeric fiber at distance $0.85 \mathrm{~m}$. The obtained characteristics can be used for luminescent properties optimization of fluorescent organic-dye-doped PMMA fiber.
\end{abstract}

Keywords: polymer optical fiber; poly(methyl methacrylate); Oxazine 170 perchlorate; fluorescence

\section{Introduction}

The organic electronics became an alternative for inorganic based light generation technology since the reliability of organic based devices has been significantly improved [1]. The main issue of the organic light emitting devices is instability of their properties in terms of environmental factors [2]. Organic materials can react with oxygen and $\mathrm{OH}^{-}$ions (humidity) and create modified structures, quenching the luminescence. Additionally, the photobleaching effects can occur when exposed to high-intensity radiation. Moreover, the UV and temperature degradation of the organic host also limit their applications [3]. Nevertheless, the much higher quantum efficiency and low energy consumption of organic dyes based devices is a significant advantage. Low-cost processability and environmentally friendly technology are attractive for high volume production. In fact, the energy saving displays and light sources based on Organic Light Emitting Devices (OLED) technology are the most promising candidates for future commercial applications [4]. Luminescent organic technology can be also successfully applied in optical fiber applications. The limitation of polymeric fibers is high attenuation (an order of $180 \mathrm{~dB} / \mathrm{km}$ at $650 \mathrm{~nm}$ ) in comparison with silica based fibers (below $0.2 \mathrm{~dB} / \mathrm{km}$ at $1550 \mathrm{~nm}$ ). In fact, high signal attenuation limits the polymeric optical fiber (POF) applications to short distance communication, compact light sources and optical sensors $[5,6]$. There are reported numerous constructions of POFs based optical sensors for liquids and gasses monitoring [7-10]. In addition, the possibility of incorporation of luminescent dopants significantly extends the application field of optical fiber devices [11-15].

Unlike silica optical fibers, POFs are mostly fabricated as multimode fibers. Moreover, the using of much thicker fibers (significantly higher flexibility of polymeric materials) allows easy and efficient connection to light sources and detectors and makes it proper solution for inexpensive data transmission applications and sensors [7]. There are reported several constructions of POFs fibers: well-known core-cladding (step and gradient index profile) and sophisticated (single-mode, 
non-linear, photonic band gap, and microstructured) polymer optical fibers [16-21]. Additionally, the waveguiding properties of optical fibers give an opportunity to radiative energy conversion or amplification. Optical fiber fabrication (drawing technique or extrusion) is mostly based on well developed textile fiber technology [21]. In fact, the low thermal conductivity of polymers limits drawing technology to the laboratory and low-level scale production. The high volume production of polymeric optical fibers is based on extrusion technique of acrylic thermoplastic granules or direct in process polymerization [22-24]. So far, the poly(methyl methacrylate), well known as organic glass, is the most frequently used one in optical fiber technology as it assures low absorption in visible spectrum range, excellent mechanical and processing properties and low cost. The PMMA was developed in the 30s of the 20th century and now is commercially used in numerous optical application (lenses, LEDs, light sources covers and optical fibers) [25-27]. Unfortunately, its structure $\left(\mathrm{C}_{5} \mathrm{H}_{8} \mathrm{O}_{2}\right)_{\mathrm{n}}$ causes Rayleigh scattering for short wavelengths part of the optical spectrum and molecular absorption for longer wavelengths. In such circumstances, the lowest attenuation is observed for visible spectrum range for four optical windows 465, 525, 565 and $650 \mathrm{~nm}$. The lowest attenuation (c.a. $40 \mathrm{~dB} / \mathrm{km}$ ) is observed for window $525 \mathrm{~nm}$ [28]. Significantly higher attenuation in the red part of VIS and IR range comes from the absorption of carbon-hydrogen overtone bond vibration. The telecommunication windows typically fall in the near infra-red region (850-1550 nm). In such circumstances, polymer technology exhibits significant limitation but, the infrared spectrum of acrylic polymers can be modified by hydrogen atoms substitution. The replacement of hydrogen with a heavier atom causes the fundamental vibration of a $\mathrm{C}-\mathrm{X}$ to shift into longer wavelengths (the attenuation is determined by higher vibration overtones). Several atoms were investigated so far: carbon-deuterium C-D, carbon-fluorine C-F, and carbon-chlorine $\mathrm{C}-\mathrm{Cl}$ can be successfully applied to reduce attenuation in desired telecommunication spectrum range. Unfortunately, the atom substitution process is very expensive and limits practical application of modified polymers. The reasonable cost-performance effect was obtained using fluorinated polymers since they have yielded the lowest minimum losses $(10 \mathrm{~dB} / \mathrm{km}$ at $1000 \mathrm{~nm})$ so far $[29,30]$. The incorporation of luminescent dopants in polymeric optical fibers gives the opportunity to new construction development and exhibits new applications fields in optical fiber technology. Among the numerous applications, the most important are light sources, amplifiers, and sensors [31,32]. Polymeric chain structure allows directing incorporation of luminescent complexes or guest-host doping mechanism. The several techniques, described below, can be applied for efficient luminescent structures fabrications.

\subsection{Organic Dyes Doping}

The idea of laser wavelength converters based on solvent and organic dyes mixtures can be successfully applied in a rigid polymer host. Organic dyes assure efficient luminescence at low excitation power which has to be limited as the melting temperature is c.a. $80-110^{\circ} \mathrm{C}$ in most of the thermoplastic polymers. In fact, the organic host also leads to a direct and solvent-based doping mechanism possibility. Moreover, the luminescence some of them can be modified since their properties strongly depend on the environmental conditions (temperature, solvent acidity, and polarity) [33]. The solvent-free technique is strongly desired for optical fiber drawing technique since the impurities and solvent residues cause the main problems (e.g., volume bobbling) during heating the preform. In addition, the organic dye-doped polymers provide interesting fluorescence properties as they assure high doping level, efficient luminescence in visible and near infrared spectrum and high quantum yield despite a short lifetime of the excited state (typically few ns) [34-36]. The disadvantage of using organic luminescent markers is photobleaching effect, especially for high energy excitation radiation. The most efficient luminescence of organic dyes is observed for xanthenes group. In fact, the highest quantum yield is reported for Rhodamine 6G (0.95) and Fluorescein (0.90) [33]. Oxazine chromophore can be obtained by replacing the xanthenes central carbon atom by nitrogen. Additionally, atom substitution is the $\pi$-electron source; the red shift of luminescence spectrum (c.a. $80 \mathrm{~nm}$ ) can then be observed [33]. In such conditions, the emission in the red part of the visible spectrum can be easily 
obtained. In opposite to oxazines, one of the most efficient laser dyes in the VIS shorter wavelengths (blue and green) range can be obtained by coumarins. Their fluorescence properties (absorption and fluorescence spectra) strongly depend on the solvent polarity. The highly efficient fluorescence was observed in numerous 7-Aminocoumarines compounds [37,38].

\subsection{Organometallic Lanthanide Complexes}

The lanthanide ions are very attractive due to their well defined multi-peak luminescence spectrum, long excited state lifetime and stable emission properties. The numerous rare earth ions $\left(\mathrm{Nd}^{3+}, \mathrm{Sm}^{3+}, \mathrm{Tb}^{3+}, \mathrm{Eu}^{3+}, \mathrm{Dy}^{3+}, \mathrm{Yb}^{3+}, \mathrm{Pr}^{3+}, \mathrm{Ho}^{3+}, \mathrm{Er}^{3+}, \mathrm{Tm}^{3+}\right)$ can be used for luminescent applications [39]. Unfortunately, the directly doped polymers exhibit weak luminescence since absorption spectrum of lanthanide ions is very narrow. The improving of luminescence efficiency can be obtained by chelation of lanthanide ions ( $\mathrm{Ln}^{3+}$ complexes). Antenna effect is used then for energy transfer from organic ligand (wide absorption band) to luminescent rare earth ion. The $\beta$-diketones, carboxylic acid derivatives, terphenyl ligands, and proteins sensitization were reported in the literature [39-44]. Additionally, the luminescence of most of the lanthanide complexes is quenched by organic groups in the polymeric host, especially for the NIR-emitting ions and efficient luminescence in the visible spectrum of PMMA host is reported only for europium $\mathrm{Eu}^{3+}$ and terbium $\mathrm{Tb}^{3+}$ organometallic complexes [45].

\subsection{Lanthanide Ions-Doped Inorganic Nanoparticles}

Nowadays, the remarkable progress can be noticed in luminescent nanocomposites. The luminescence quenching by the polymeric host can be reduced by the controlled low phonon energy local environment of luminescent centers. Phonon energies of some common inorganic materials (e.g., chalcogenide or fluoride glass, $\mathrm{CaF}_{2}, \mathrm{LaF}_{3}, \mathrm{LaCl}_{3}$ crystals) allows obtaining efficient luminescence since the reduction of non-radiative transitions occurs [46-49]. The several types of core-shell structures with enhanced luminescence properties of nanocrystals were investigated. In such circumstances, they have potential as optical active structures where nanoparticles are dispersed in a polymeric host. The promising telecommunication spectrum ranges of polymeric active waveguides have been investigated using $\mathrm{Nd}^{3+}(1320 \mathrm{~nm})$ and $\mathrm{Er}^{3+}(1536 \mathrm{~nm})$ nanoparticles [47].

\subsection{Oxazine 170 Perchlorate Doped PMMA}

The organic dyes typically can be easily incorporated in PMMA matrix using solvent-free technique preserving its high fluorescence efficiency. Beside the xanthenes, the oxazines are one of the most frequently used laser dyes for the VIS (red) and near-IR [33]. The Oxazine 170 perchlorate main absorption band is situated at $621 \mathrm{~nm}$ since the emission spectrum, according to mirror symmetry, is situated at $648 \mathrm{~nm}$ as presented in Figure 1.

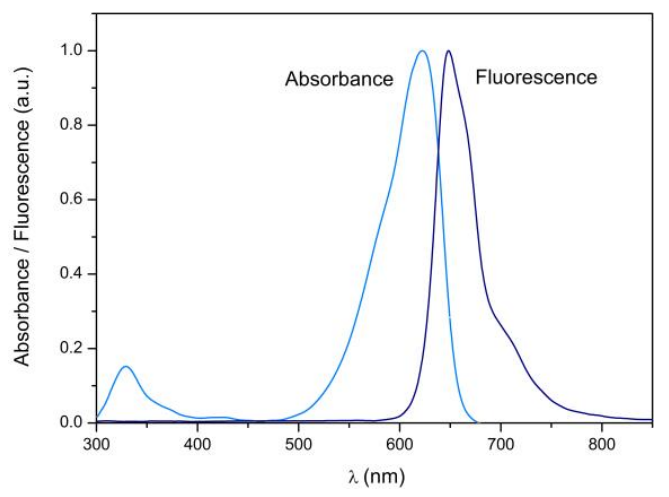

Figure 1. Measured normalized absorbance/fluorescence spectra of Oxazine 170 perchlorate in ethanol, fluorescence measured at excitation $593.5 \mathrm{~nm}$. 
Under such circumstances, the oxazines are promising laser dyes for $650 \mathrm{~nm}$ PMMA optical window which is the most interesting since there are available low-cost laser diode sources (InGaAs) and high sensitivity silicon photodiodes. The polymeric host typically slightly shifts (a few $\mathrm{nm}$ ) the emission spectrum into the longer wavelengths. Moreover, the high quantum yield $\left(0.63, \mathrm{CH}_{3} \mathrm{OH}\right)$ and melting temperature c.a. $260^{\circ} \mathrm{C}$ make it a proper candidate for optical fiber drawing technology [33,50]. It is worth to note that in the visible range the highest attenuation of PMMA core optical fibers (typically $610-640 \mathrm{~nm}$ ) is noticeable for maximum absorption of Oxazine 170 perchlorate. The high PMMA absorption of excitation radiation can be overcome by using shorter wavelength excitation since the pump radiation affecting length can be significantly longer than in bulk samples. In such case, the excitation pump radiation wavelength can be shifted into the $525 \mathrm{~nm}$ transmission window observed in the step index profile of PMMA fiber [28] where Nd:YAG, the second harmonic wavelength $(532 \mathrm{~nm})$ laser radiation can be used. In fact, the high quantum yield of organic laser dyes allows efficient light amplification on the short distances (tenths of $\mathrm{cm}$ ) in comparison with lanthanide ions doped silica amplifiers (tenths of $\mathrm{m}$ ) [31]. Moreover, the big core diameter and high optical aperture of PMMA fluorinated cladding fibers allow effective coupling of optical radiation with co-working electronic devices (light sources and detectors).

\section{Materials and Methods}

The raw materials: Methyl Methacrylate (MMA), Benzoyl Peroxide (BP), and Oxazine 170 perchlorate were supplied by Sigma-Aldrich (St. Louis, MO, USA). The stabilizer agent has been removed from the monomer before free radical polymerization process of preform fabrication $(48 \mathrm{~h}$ at $67-80^{\circ} \mathrm{C}$ ). The PMMA doping was performed directly during the polymerization process (Ox170 molar concentration $4.3 \times 10^{-5}$ ) and $15 \mathrm{~mm}$ outer diameter preform was obtained. No visible polymerization defects were observed in the preform. The fiber $(1.6 \mathrm{~mm}$ diameter, presented in Figure 2) was fabricated using computer controlled optical fiber tower. The process parameters were as follows: furnace temperatures $\mathrm{T}=160-185^{\circ} \mathrm{C}$, preform feeding $0.3 \mathrm{~cm} / \mathrm{min}$, drawing speed $32-62 \mathrm{~cm} / \mathrm{min}$. Chosen fiber diameter assures high fluorescence signal at low excitation laser power density which has to be limited since glass transition temperature of PMMA is c.a. $105^{\circ} \mathrm{C}$.

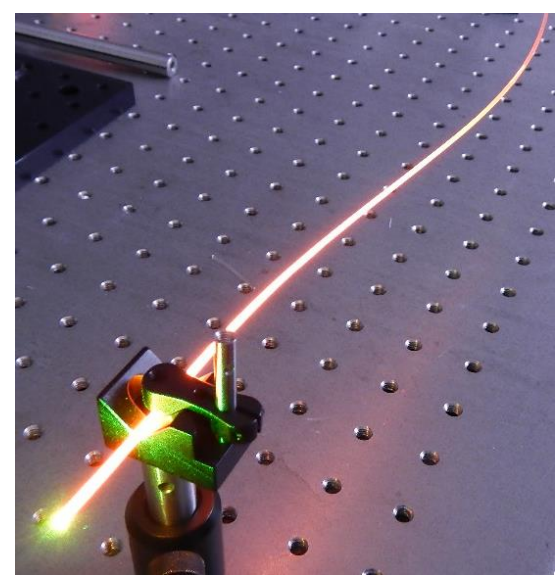

Figure 2. The photo of Oxazine 170 perchlorate doped PMMA fiber under $532 \mathrm{~nm}$ excitation.

The one end excitation and fiber cutback methods were used for fluorescence spectra measurements. The luminescence signal was collected from the end of the fibre. The solid state, diode pumped laser $(532 \mathrm{~nm}, \mathrm{FWHM}=10 \mathrm{~nm})$ was used as excitation source. All spectra were measured using an optical fiber-coupled Stellarnet Green Wave spectrometer in the range of 500-850 nm at a resolution of $0.5 \mathrm{~nm}$. 


\section{Results}

Under the $532 \mathrm{~nm}$ excitation, the intense lateral fluorescence can be noticed (Figure 2). The measured effective pumping length was $50 \mathrm{~mm}$ (at 1\% initial power criterion). The used excitation radiation power $(37 \mathrm{~mW})$ has to be limited due to the fact of low damage threshold of PMMA. The luminescence spectrum shift can be noticeable due to reabsorption of luminescence signal in PMMA fibre. The maximum of excitation spectrum, presented in Figure 3, is situated at $615 \mathrm{~nm}$. The used laser diode $(532 \mathrm{~nm})$ allows an intense fluorescence due to the effective excitation of Ox170. The longer wavelength shift effect expected in organic dye-doped fibers is also noticeable in Figure 2.

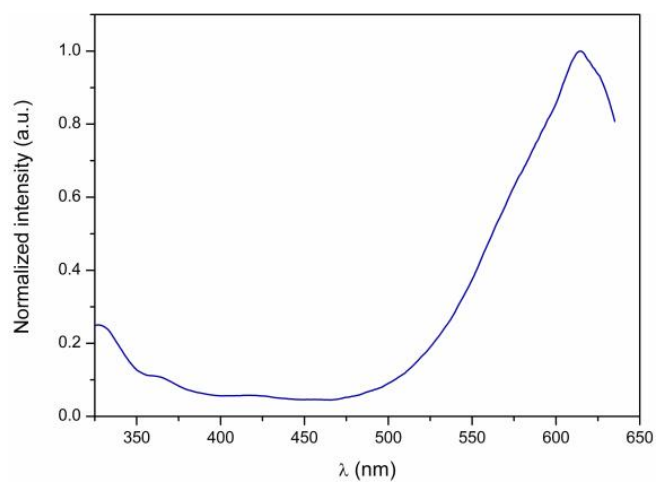

Figure 3. The normalized excitation spectrum of Ox170 perchlorate doped PMMA.

The laser source used for fibre excitation has significantly shorter wavelength than Ox170 maximum excitation spectrum (615 nm, as presented in Figure 3). In such circumstances, the wider fluorescence signal range of can be observed vs. the fiber length.

In fact, the combination of the long affecting length of excitation radiation, reabsorption properties of organic dye and spectral attenuation of PMMA host change the fluorescence spectrum shape in polymeric fiber. The measured normalized fluorescence spectra for different lengths of the fibre are presented in Figure 4. The significant spectral shape modification and so-called "red shift" effect can be noticed. Moreover, the monotonic $\lambda_{\max }$ increasing tendency is clearly visible. The maximum of the luminescent peak for Ox170 can be observed in the range from 619 up to $697 \mathrm{~nm}$ as presented in Figure 5a. The further analysis allows to observe that significant change of $\lambda_{\max }$ (average slope $4.6 \mathrm{~nm} / \mathrm{cm}$ ) can be noticed for fiber length $0.02-0.10 \mathrm{~m}$ and corresponds to the overlap spectral region (620-655 nm) of absorbance and fluorescence spectra of Ox170 (Figure 1). Outside this range, the reabsorption is much weaker and the characteristic average slope is lower (c.a. $0.56 \mathrm{~nm} / \mathrm{cm}$ ) for fiber length $0.10-0.85 \mathrm{~m}$.

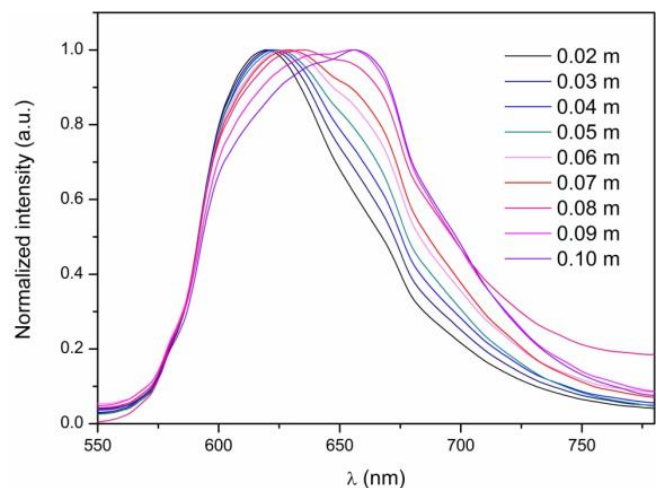

(a)

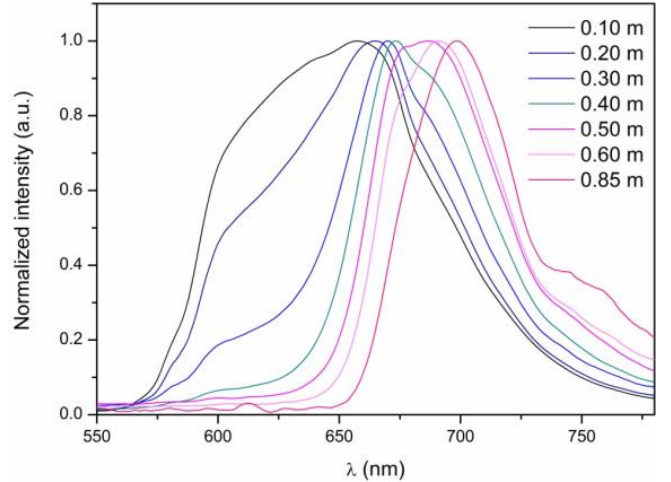

(b)

Figure 4. The normalized fluorescence spectra of Ox170 doped fiber: (a) 0.02-0.10 m; (b) 0.10-0.85 m. 
The full width at half maximum (FWHM) of recorded spectra is presented in Figure $5 \mathrm{~b}$. The chosen excitation wavelength is shorter than the maximum of the absorption spectrum of Oxazine 170 perchlorate and FWHM fast increasing can be noticed then (slope $6.7 \mathrm{~nm} / \mathrm{cm}$ ). Moreover, the broadening of luminescence spectrum is the result of the more efficient excitation of organic molecules since luminescence peak shifts $\left(\lambda_{\max }\right)$ are observed in the maximum of excitation spectrum of Ox170. The FWHM maximum $(105 \mathrm{~nm})$ is observed for fiber length $0.08 \mathrm{~m}$ and corresponds to the fluorescence $\lambda_{\max }$ of Ox170 $(650 \mathrm{~nm})$. The monotonic decreasing tendency of FWHM is observed for distances longer than $0.08 \mathrm{~m}\left(\lambda_{\max }>650 \mathrm{~nm}\right)$ and is resulted by reabsorption of fluorescence radiation in dye-doped polymeric fiber. The nearly linear dependence can be noticed for fiber length longer than $0.3 \mathrm{~m}$ since the luminescence wavelength is situated on the right tail of Ox170 fluorescence spectrum. The decreasing of spectrum width is expected then as the absorption plays a significant role in the final luminescence spectrum shape.

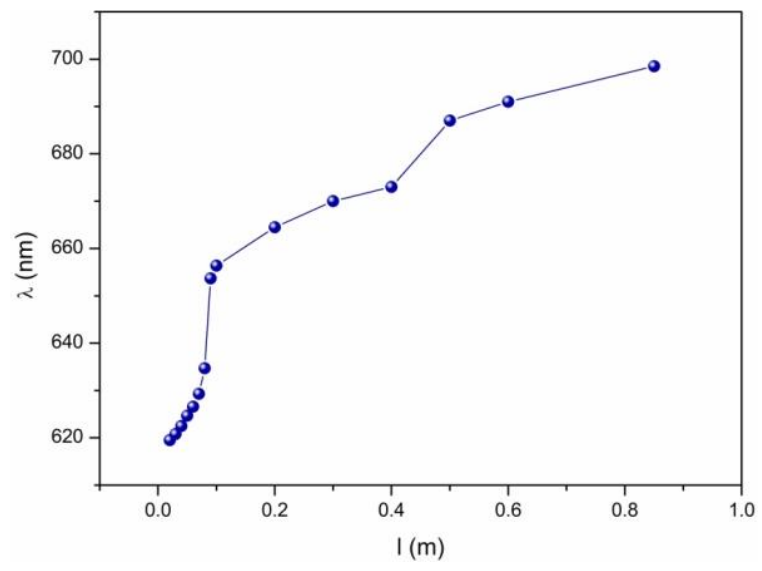

(a)

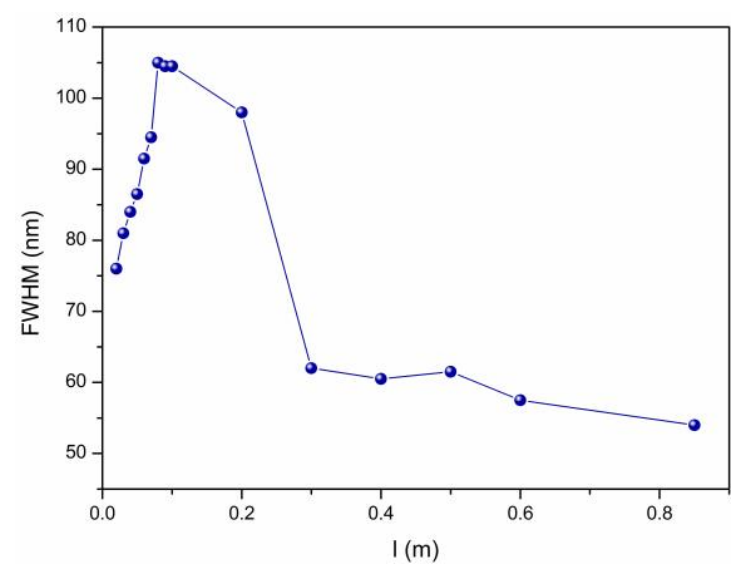

(b)

Figure 5. (a) The $\lambda_{\max }$ shift vs. fiber length; (b) The FWHM of luminescence spectrum vs. fiber length.

The absorption of Ox170 molecules causes strong signal attenuation. The significant spectrum shape modification $\left(\lambda_{\max }\right.$ and FWHM) can be observed then. Measured attenuation for fluorescence signal $\left(\lambda_{\max }\right)$ slope equals $18.5 \mathrm{~dB} / \mathrm{m}$ and is presented in Figure 6 . High attenuation of fluorescence signal limits the useful fiber length. In fact, the organic dyes doped polymeric luminescent fibers length is limited to tenths of centimeters. The measured fluorescent properties of Ox170 doped PMMA fiber strongly correspond to spectroscopic properties of the used dye. The $\lambda_{\max }$ and FWHM of fluorescence spectra can be directly interpreted using absorption end emission spectra of Ox170. Moreover, the possibility of fluorescent spectrum shape modification can be used in numerous optical application and desired fluorescence spectrum can be obtained using optimized POFs. The significant red shift of $\lambda_{\max }$ c.a. $80 \mathrm{~nm}$ can be obtained at distance $0.85 \mathrm{~m}$ in presented polymeric optical fiber. The bright fluorescence of Ox170 in PMMA fiber can be used for specific light conversion. Moreover, the presented interesting properties of dye-doped PMMA fibre can be used in new optical fiber applications since the advantages of polymeric optical fibers (high flexibility at big core diameter, high numerical aperture) are often desired in new compact light sources [51]. 


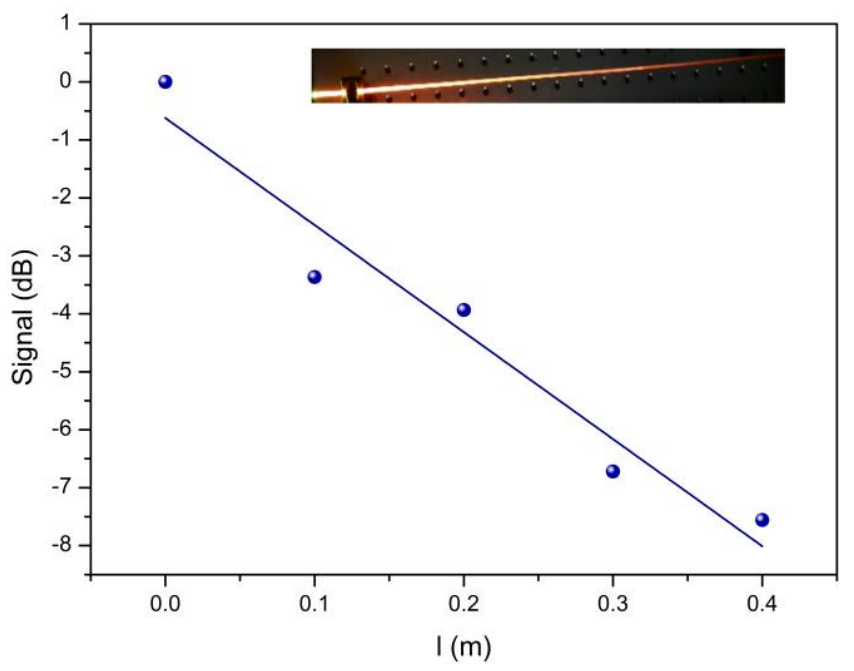

Figure 6. The luminescence signal attenuation vs. fiber length.

\section{Conclusions}

Luminescent polymers are promising materials for photonic applications. The well-developed technology of POFs and several techniques of host doping mechanisms make them a good alternative for silica-based optical fibers. In fact, a new class of organic-inorganic materials can be obtained by polymer host doping. The core-shell structures and co-doped photonic materials can be also investigated. Moreover, low processing temperatures of acrylates allow optical fibre drawing for a wide range of dopants (organic and inorganic). In the article, the incorporation of Oxazine 170 perchlorate in PMMA host process and fabricated fiber was presented. The bright fluorescence of polymeric fiber was obtained under $532 \mathrm{~nm}$ excitation. Remarkable luminescence parameters changes ( $\lambda_{\max }$ red shift; average slope: $4.6 \mathrm{~nm} / \mathrm{cm}$; FWHM increasing slope: $6.7 \mathrm{~nm} / \mathrm{cm}$ ) can be noticed for the overlapping region of absorption and emission spectra of used dye. In fact, the total $\lambda_{\max }$ shift c.a. $80 \mathrm{~nm}$ was obtained in presented polymeric fiber $(0.85 \mathrm{~m})$. The obtained results can be used for new optical radiation conversion applications.

Acknowledgments: This work was supported by Bialystok University of Technology project No. S/WE/4/2013, Poland and under EU COST Action MP1401 "Advanced fibre laser and coherent source as tools for society, manufacturing and life science".

Conflicts of Interest: The author declares no conflict of interest.

\section{References}

1. Williams, G.; Backhouse, C.; Aziz, H. Integration of organic light emitting diodes and organic photodetectors for lab-on-a-chip bio-detection systems. Electronics 2014, 3, 43-75. [CrossRef]

2. Zardareh, S.Z.; Boroumand, F.A. Degradation in organic light emitting diodes. World Acad. Sci. Eng. Technol. 2009, 50, 274-277.

3. Kwak, K.; Cho, K.; Kim, S. Analysis of thermal degradation of organic light emitting diodes with infrared imaging and impedance spectroscopy. Opt. Express 2013, 21, 29558-29566. [CrossRef] [PubMed]

4. Zissis, G.; Bertoldi, P. 2014 Status report on organic light emitting diodes (OLED). Eur. Comm. Jt. Res. Cent. 2014. [CrossRef]

5. Peng, G.-D.; Ji, N.P.; Wang, T. Development of special polymer optical fibres and devices. Proc. SPIE 2004, $5595,138-152$.

6. Zubia, J. Plastic optical fibers: An introduction to their technological processes and applications. Opt. Fiber Technol. 2001, 7, 101-114. [CrossRef]

7. Bilro, L.; Alberto, N.; Pinto, J.L.; Nogueira, R. Optical Sensors Based on Plastic Fibers. Sensors 2012, 12, 12184-12207. [CrossRef] [PubMed] 
8. Montero, D.S.; Vázquez, C.; Möllers, I.; Arrúe, J.; Jäger, D. A self-referencing intensity based polymer optical fiber sensor for liquid detection. Sensors 2009, 9, 6446-6455. [CrossRef] [PubMed]

9. Grassini, S.; Ishtaiwi, M.; Parvis, M.; Vallan, A. Design and deployment of low-cost plastic optical fiber sensors for gas monitoring. Sensors 2015, 15, 485-498. [CrossRef] [PubMed]

10. Moraleda, A.T.; García, C.V.; Zaballa, J.Z.; Arru, J. A temperature sensor based on a polymer optical fiber macro-bend. Sensors 2013, 13, 13076-13089. [CrossRef] [PubMed]

11. Miluski, P.; Dorosz, D.; Żmojda, J.; Kochanowicz, M.; Dorosz, J. Luminescent polymer optical fibre sensor for temperature measurement. Acta Phys. Pol. A 2015, 127, 730-733. [CrossRef]

12. Miluski, P.; Dorosz, D.; Kochanowicz, M.; Zmojda, J.; Dorosz, J. Luminescent optical fibre sensor for UV-A detection. Proc. SPIE 2014. [CrossRef]

13. Wang, X.; Wolfbeis, O.S. Optical methods for sensing and imaging oxygen: Materials, spectroscopies and applications. Chem. Soc. Rev. 2014, 43, 3666-3761. [CrossRef] [PubMed]

14. Miluski, P.; Dorosz, D.; Kochanowicz, M.; Zmojda, J.; Dorosz, J. The xanthene dyes doped PMMA microspheres for optical sensors applications. Proc. SPIE 2015. [CrossRef]

15. Zmojda, J.; Kochanowicz, M.; Miluski, P.; Dorosz, D. Side-detecting optical fiber doped with $\mathrm{Tb}^{3+}$ for ultraviolet sensor application. Fibers 2014, 2, 150-157. [CrossRef]

16. Eijkelenborg, M.A.; Argyros, A.; Barton, G.; Bassett, I.M.; Fellew, M.; Henry, G.; Issa, N.A.; Large, M.C.J.; Manos, S.; Padden, W.; et al. Recent progress in microstructured polymer optical fibre fabrication and characterisation. Opt. Fiber Technol. 2003, 9, 199-209. [CrossRef]

17. Silva-López, M.; Fender, A.; MacPherson, W.N.; Barton, J.S.; Jones, J.D.C. Strain and temperature sensitivity of a single-mode polymer optical fiber. Opt. Lett. 2005, 30, 3129-3131. [CrossRef] [PubMed]

18. Markos, C.; Kubat, I.; Bang, O. Hybrid polymer photonic crystal fiber with integrated chalcogenide glass nanofilms. Sci. Rep. 2014, 6057, 1-7. [CrossRef] [PubMed]

19. Woliński, T.; Tefelska, M.; Mileńko, K.; Siarkowska, A.; Budaszewski, D.; Domański, A.; Ertman, S.; Orzechowski, K.; Rutkowska, K.; Sierakowski, M.; et al. Photonic liquid crystal fibers with polymers. Acta Phys. Pol. A 2013, 124, 613-616. [CrossRef]

20. Argyros, A.; Eijkelenborg, M.A.; Large, M.C.J.; Bassett, I.M. Hollow-core microstructured polymer optical fiber. Opt. Lett. 2006, 31, 172-174. [CrossRef] [PubMed]

21. Needles, H.L. Textile Fibers, Dyes, Finishes, and Processes: A Concise Guide; ISBN: 0-8155-1076-4. Noyes Publications: Park Ridge, NJ, USA, 1986.

22. Mignanelli, M.; Wani, K.; Ballato, J.; Foulger, S.; Brown, P. Polymer microstructured fibers by one-step extrusion. Opt. Lett. 2007, 15, 6183-6189. [CrossRef]

23. Ebendorff-Heidepriem, H.; Monro, T.M. Extrusion of complex preforms for microstructured optical fibers. Opt. Lett. 2007, 15, 15086-15092. [CrossRef]

24. Lethien, C.; Loyez, C.; Vilcot, J.P.; Rolland, N.; Rolland, P.A. Exploit the bandwidth capacities of the perfluorinated graded index polymer optical fiber for multi-services distribution. Polymers 2011, 3, 1006-1028. [CrossRef]

25. Yeh, S.L.; Zhu, C.Y.; Kuo, S.W. Transparent heat-resistant PMMA copolymers for packing light-emitting diode materials. Polymers 2015, 7, 1379-1388. [CrossRef]

26. Nespola, A.; Abrate, S.; Gaudino, R.; Zerna, C.; Offenbeck, B.; Weber, N. High-speed communications over polymer optical fibers for in-building cabling and home networking. IEEE Photonics J. 2010, 2, 347-358. [CrossRef]

27. Tafur Monroy, I.; Boom, H.P.A.; Koonen, A.M.J.; Khoe, G.D.; Watanabe, Y.; Koike, Y.; Ishigure, T. Data transmission over polymer optical fibers. Opt. Fiber Technol. 2003, 9, 159-171. [CrossRef]

28. Fischer, U.H.P.; Haupt, M.; Joncic, M. Optical Transmission Systems Using Polymeric Fibers. In Optoelectronics_Devices and Applications; ISBN: 978-953-307-576-1. 2011; Available online: http://cdn. intechopen.com/pdfs/20494/InTech-Optical_transmission_systems_using_polymeric_fibers.pdf (accessed on 21 February 2017).

29. Kuzyk, M.G. Polymer Fiber Optics. Materials, Physics, and Applications; ISBN: 1-57444-7068-8; Taylor \& Francis Group: Boca Raton, FL, USA, 2007.

30. Khanarian, G.; Celanese, H. Optical properties of cyclic olefin copolymers. Opt. Eng. 2001, 40, 1024-1029. [CrossRef] 
31. Arrue, J.; Jiménez, F.; Ayesta, I.; Asunción Illarramendi, M.; Zubia, J. Polymer-optical-fiber lasers and amplifiers doped with organic dyes. Polymers 2011, 3, 1162-1180. [CrossRef]

32. Karimi, M.; Granpayeh, N.; Morraveg Farshi, M.K. Analysis and design of a dye-doped polymer optical fiber amplifier. Appl. Phys. B 2004, 78, 387-396. [CrossRef]

33. Drexhage, K.H. Fluorescence Efficiency of Laser Dyes. J. Res. Natl. Bur. Stand. A 1976, 3, 421-428. [CrossRef]

34. Sheeba, M.; Rajesh, M.; Nampoorj, V.P.N.; Radhakrishnan, P. Fabrication and characterization of dye mixture doped polymer optical fiber as a broad wavelength optical amplifier. Appl. Opt. 2008, 47, 884-889. [CrossRef]

35. Kailasnath, M.; Kumar, N.; Nampoori, V.P.N.; Vallabhan, C.P.G.; Radhakrishnan, P. Excitation wavelength dependence of energy transfer in dye mixture doped polymer optical fibre preforms. J. Photochem. Photobiol. A 2008, 199, 236-241. [CrossRef]

36. Hammond, P.R. Laser Dye Technology; United States Department of Energy: Washington, DC, USA, 1999.

37. Donovalová, J.; Cigáň, M.; Stankovičová, H.; Gašpar, J.; Danko, M.; Gáplovský, A.; Hrdlovič, P. Spectral properties of substituted coumarins in solution and polymer matrices. Molecules 2012, 17, 3259-3276. [CrossRef] [PubMed]

38. Hrdlovic, P.; Donovalova, J.; Stankovicova, H.; Gaplovsky, A. Influence of polarity of solvents on the spectral properties of bichromophoric coumarins. Molecules 2010, 15, 8915-8932. [CrossRef] [PubMed]

39. Búnzli, J.C.G.; Piguet, C. Taking advantage of luminescent lanthanide ions. Chem. Soc. Rev. 2005, 34, 1048-1077. [CrossRef] [PubMed]

40. Hebbink, G. Luminescent Materials Based on Lanthanide Ions. Ph.D. Thesis, University of Twente, G.A. Hebbink, Enschede, The Netherlands, 2002.

41. Kai, J.; Parra, D.F.; Brito, H.F. Polymer matrix sensitizing effect on photoluminescence properties of $\mathrm{Eu}^{3+}-\beta$-diketonate complex doped into poly-b-hydroxybutyrate (PHB) in film form. J. Mater. Chem. 2008, 18, 4549-4554. [CrossRef]

42. Chen, B.; Dong, N.; Xu, J.; Liang, H.; Luo, Y.; Wang, C.; Wu, W.; Wang, H. Optical properties and spectroscopic parameters of Sm(TTA $)_{3}(\mathrm{TPPO})_{2}$ doped PMMA. Optoelectron. Adv. Mater. Rapid Commun. 2007, 1, 609-613.

43. Escribano, P.; Julián-López, B.; Planelles-Aragó, J.; Cordoncillo, E.; Viana, B.; Sanchez, C. Photonic and nanobiophotonic properties of luminescent lanthanide-doped hybrid organic-inorganic materials. J. Mater. Chem. 2008, 18, 23-40. [CrossRef]

44. Liang, H.; Yang, Z.; Xiao, L.; Xie, F. Radiative transition probability of a europium (III) chelating polymer. Optoelectron. Adv. Mater. Rapid Commun. 2010, 4, 1396-1399.

45. Jiu, H.; Ding, J.; Sun, Y.; Bao, J.; Gao, C.; Zhang, Q. Fluorescence enhancement of europium complex co-doped with terbium complex in a poly(methyl methacrylate) matrix. J. Non-Cryst. Solids 2006, 352, 197-202. [CrossRef]

46. Chen, X.; Yan, B. In situ composition and photoluminescence of Tb, Eu centers/PMMA hybrid polymeric thick films. J. Optoelectron. Adv. Mater. 2006, 8, 1931-1934.

47. Stouwdam, J.W. Lanthanide-Doped Nanoparticles As the Active Optical Medium in Polymer-Based Devices. Ph.D. Thesis, Netherlands Organisation for Scientific Research, Hague, The Netherlands, 2004.

48. Kumar, G.A.; Chen, C.W.; Riman, R.; Chen, S.; Smith, D.; Ballato, J. Optical properties of a transparent $\mathrm{CaF}_{2}: \mathrm{Er}^{3+}$ fluoropolymer nanocomposite. Appl. Phys. Lett. 2005, 86. [CrossRef]

49. Fischer, S.; Johnson, N.J.J.; Pichaandi, J.; Goldschmidt, J.C.; van Veggel, F.C.J.M. Upconverting core-shell nanocrystals with high quantum yield under low irradiance: On the role of isotropic and thick shells. J. Appl. Phys. 2015, 188. [CrossRef]

50. Du, H.; Fuh, R.A.; Li, J.; Corkan, L.A.; Lindsey, J.S. PhotochemCAD: A computer-aided design and research tool in photochemistry. Photochem. Photobiol. 1998, 68, 141-142.

51. Miluski, P.; Dorosz, D.; Kochanowicz, M.; Żmojda, J. Fluorescent polymeric optical fibre illuminator. Electron. Lett. 2016, 52, 1550-1552. [CrossRef]

(C) 2017 by the author. Licensee MDPI, Basel, Switzerland. This article is an open access article distributed under the terms and conditions of the Creative Commons Attribution (CC BY) license (http:/ / creativecommons.org/licenses/by/4.0/). 